\title{
Persistent depression is a significant risk factor for the development of arteriosclerosis in middle-aged Japanese male subjects
}

\begin{abstract}
Hiroki Satoh $^{1,2}$, Satoshi Fujii ${ }^{3}$ and Hiroyuki Tsutsui ${ }^{2}$
Depression often coexists with hypertension and various cardiovascular diseases. However, the relationship between depression and the development of arteriosclerosis has not been fully established. We assessed depression and brachial-ankle pulse wave velocity (baPWV) in 828 middle-aged Japanese male subjects at baseline and during 3 years of follow-up. Depression was assessed using Center for Epidemiological Studies-Depression questionnaires, and the study subjects were divided into the following three groups: persistent depression, transient depression and no depression. The number (\%) of subjects with persistent, transient and no depression were 104 (12.6), 76 (9.2) and 648 (78.2), respectively. Blood pressure and baPWV did not differ among the three groups at baseline. The changes in the baPWV values ( $\triangle$ baPWV) correlated significantly and positively with age, body mass index, baseline systolic blood pressure and persistent depression $(r=0.32, P<0.01)$. After 3 years of follow-up, the $\triangle \mathrm{baPWV}$ was significantly greater in subjects with persistent depression compared with those with no depression $\left(36 \pm 28\right.$ vs. $\left.18 \pm 10 \mathrm{~cm} \mathrm{~s}^{-1}, P=0.02\right)$. After adjustment for conventional risk factors, persistent depression was significantly associated with $\triangle$ baPWV by multiple regression analysis $(\beta=0.261, P<0.01)$. To sum up, persistent depression was a significant risk factor for the development of arteriosclerosis in middle-aged Japanese male subjects. Hypertension Research (2015) 38, 84-88; doi:10.1038/hr.2014.137; published online 25 september 2014
\end{abstract}

Keywords: arteriosclerosis; depression; epidemiology; Japanese subjects

\section{INTRODUCTION}

Depression is highly prevalent, and the lifetime incidence of depression has been estimated to be $16 \%$ in the general population. ${ }^{1}$ The World Health Organization reported that an estimated $5.8 \%$ of men and $9.5 \%$ of women in the general population experience episodes of depression during a 12 -month period. ${ }^{2}$ Depression has been shown to be closely associated with the occurrence of diabetes mellitus, hypertension, coronary heart disease and stroke. ${ }^{3-10}$ Previous experimental studies demonstrated that depressive behavior accelerated arteriosclerosis in monkeys. ${ }^{11}$ Studies in humans also demonstrated that depression was associated with the development of arteriosclerosis based on assessments of coronary, carotid and aortic artery calcifications. ${ }^{12,13}$ In contrast, other studies could not confirm this association by using carotid-femoral aortic pulse wave velocity and coronary artery calcification. ${ }^{14,15}$ However, these studies defined depression as the transient presence of depressive symptoms, and the effects of persistent depression on the development of arteriosclerosis during the follow-up period were not examined. Chronic depression rather than transient depressive symptoms may be associated with the development of arteriosclerosis. ${ }^{16}$
In the present study, the presence of depression and arteriosclerosis was examined at baseline and every year during 3 years of follow-up. The purpose of the present study was to examine the relationship between persistent depression and the development of arteriosclerosis in middle-aged Japanese male subjects.

\section{METHODS}

\section{Study subjects}

We enrolled 1068 male employees working at a food and beverage company who ranged in age from 42 to 57 years and had their annual health examinations between April 2009 and March 2012. A total of 215 subjects were excluded; of these subjects, 189 were undergoing medical treatment for hypertension (diagnosed as systolic blood pressure $\geqslant 140 \mathrm{~mm} \mathrm{Hg}$ and/or diastolic blood pressure $\geqslant 90 \mathrm{~mm} \mathrm{Hg}$ at the annual health examination), 10 had cardiovascular disease and 16 had depression requiring medical treatment. Twenty-five subjects (2.3\%) were lost to follow-up. Hypertensive patients were excluded because hypertension is an important and major risk factor for the development of arteriosclerosis. The degree of arteriosclerosis might differ among the study subjects at baseline, and it might be difficult to adjust the types and doses of antihypertensive drugs in the statistical analysis. Thus, 828 subjects remained in the present study. The study protocol was approved by the ethics

${ }^{1}$ Department of Medical Management and Informatics, Hokkaido Information University, Ebetsu, Japan; ${ }^{2}$ Department of Cardiovascular Medicine, Hokkaido University Graduate School of Medicine, Sapporo, Japan and ${ }^{3}$ Department of Molecular and Cellular Pathobiology and Therapeutics, Nagoya City University Graduate School of Pharmaceutical Sciences, Nagoya, Japan

Correspondence: Dr H Satoh, Department of Clinical Management and Informatics, Hokkaido Information University, 59-2, Nishi-Nopporo, Ebetsu, Hokkaido 069-8585, Japan. E-mail: h-satoh@do-johodai.ac.jp

Received 2 December 2013; revised 15 July 2014; accepted 21 July 2014; published online 25 september 2014 
committee of Hokkaido Information University, and written informed consent was obtained from each subject.

\section{Baseline characteristics of the study subjects}

The baseline characteristics of the study subjects, including smoking habit, alcohol consumption, frequency of exercise, family history of hypertension and medical history were examined using a self-questionnaire. Subjects who had never smoked and ex-smokers were classified as 'non-smokers'. Drinkers were defined as those who consumed alcohol once per week or more. Exercise was defined as regular exercise performed more than once per week. Body mass index (BMI) was calculated as body weight $(\mathrm{kg})$ divided by squared height $(\mathrm{m})$. Blood pressure was measured in the sitting position after a resting period of at least $5 \mathrm{~min}$ by a trained nurse using a standard mercury sphygmomanometer. A blood sample was obtained from the antecubital vein in the morning after an overnight fast, and the serum was separated. After precipitation by heparin-manganese, total cholesterol and high-density lipoprotein-cholesterol were measured by the phosphotungstate method. Triglyceride was measured enzymatically. Glucose was enzymatically determined by the hexokinase method. High-sensitivity C-reactive protein (hs-CRP) was measured by nephelometry with a latex particle-enhanced immunoassay.

\section{Depression}

Depression was assessed using a Center for Epidemiological Studies-Depression questionnaire, which is a 20 -item self-report questionnaire covering depressed mood, feelings of worthlessness, feelings of hopelessness, poor concentration, appetite loss and sleep disturbance. ${ }^{17,18}$ The Center for Epidemiological StudiesDepression scores ranged between 0 and 60 , and scores $\geqslant 16$ were proposed as indicators of a propensity for depression. ${ }^{19,20}$ Depression was assessed at baseline and every year during the 3 years of follow-up. The subjects who had Center for Epidemiological Studies-Depression scores $\geqslant 16$ at all three examinations during the follow-up were defined as 'persistent depression'. Those who had scores $<16$ at all three examinations were defined as 'no depression'. Those who had scores $\geqslant 16$ at one or two examinations during the follow-up were defined as 'transient depression'.

\section{Brachial-ankle pulse wave velocity}

Brachial-ankle pulse wave velocity (baPWV) was measured by a volumeplethymographic apparatus (Form PWV/ABI; Colin, Komaki, Japan). ${ }^{21} \mathrm{BaPWV}$ values were recorded after at least $5 \mathrm{~min}$ of rest. This device can measure the phonocardiogram, electrocardiogram, volume pulse form and arterial blood pressure at the left and right brachia and ankles, and the time intervals between the wave front of the right brachium and those of both ankles were calculated. Ankle/brachial pressure is the ratio of ankle to brachial systolic blood pressure, and right and left ankle/brachial pressures were measured simultaneously.
We calculated the mean right and left baPWV values in the analysis. Blood pressure and baPWV values were measured at baseline and again after 3 years of follow-up. The changes in baPWV values from baseline to the end of the 3year follow-up period are defined as $\triangle \mathrm{baPWV}$.

\section{Statistical analysis}

The data are expressed as the mean \pm s.d. for continuous variables, median (and interquartile range) for skewed distribution variables and percentages for categorical variables among the three groups. The differences in variables between groups were examined by analysis of variance followed by the Bonferroni test or the $\chi^{2}$-test. Linear regression analysis was performed to evaluate the association between $\triangle \mathrm{baPWV}$ and the other variables. Subsequently, multiple linear regression analysis was used to clarify the contribution of depression to $\triangle \mathrm{baPWV}$ after adjusting for age, BMI, smoking, alcohol, exercise, family history of hypertension, total cholesterol, triglyceride, highdensity lipoprotein-cholesterol, glucose, hs-CRP and baseline systolic blood pressure. A $P$-value $<0.05$ was considered to indicate statistical significance. All statistical analyses were performed using the SPSS statistical package for Windows, version 11.0 (SPSS, Chicago, IL, USA)

\section{RESULTS}

Table 1 shows the characteristics of the study subjects and those classified according to the presence of depression. Of 828 subjects, the number (\%) of the study subjects with persistent, transient and no depression were 104 (12.6), 76 (9.2) and 648 (78.2), respectively. Age, BMI, smoking, alcohol, total cholesterol, triglyceride, high-density lipoprotein-cholesterol, glucose and hs-CRP did not differ significantly among the three groups. Subjects with persistent depression were significantly less likely to exercise regularly and significantly more likely to have a family history of hypertension compared with subjects with no depression.

Table 2 shows the changes in blood pressure values at baseline and after 3 years of follow-up. Systolic and diastolic blood pressure values at baseline and after 3 years of follow-up did not differ among the three groups.

Figure 1a shows the changes in baPWV values at baseline and after 3 years of follow-up. Baseline baPWV values were the same among the three groups; however, after 3 years of follow-up, these values were significantly higher in the subjects with persistent depression compared with those with no depression $\left(1339 \pm 111\right.$ vs. $1308 \pm 88 \mathrm{~cm} \mathrm{~s}^{-1}$, $P=0.02)$.

Table 1 Characteristics of the study subjects and those classified according to the presence of depression

Depression

\begin{tabular}{|c|c|c|c|c|c|}
\hline & Total $(\mathrm{n}=828)$ & Persistent $(\mathrm{n}=104)$ & Transient $(n=76)$ & No. $(n=648)$ & $\mathrm{P}$ for trend \\
\hline Age (years) & $50 \pm 4$ & $50 \pm 4$ & $50 \pm 3$ & $50 \pm 4$ & 0.99 \\
\hline Body mass index $\left(\mathrm{kg} \mathrm{m}^{-2}\right)$ & $23.8 \pm 2.7$ & $23.7 \pm 2.7$ & $24.0 \pm 2.8$ & $23.8 \pm 2.6$ & 0.75 \\
\hline Smoking, $n(\%)$ & $374(45.2)$ & $44(42.3)$ & $32(42.1)$ & $298(46.0)$ & 0.67 \\
\hline Alcohol, $n(\%)$ & $513(62.0)$ & $62(59.6)$ & $45(59.2)$ & $406(62.7)$ & 0.73 \\
\hline Exercise, $n(\%)$ & $186(22.5)$ & $17(16.3)^{\mathrm{a}}$ & $17(22.4)$ & $152(23.5)$ & 0.27 \\
\hline Family history of hypertension, $n(\%)$ & $122(14.7)$ & $20(19.2)^{b}$ & $11(14.5)$ & $91(14.0)$ & 0.38 \\
\hline Total cholesterol (mg dl-1) & $210 \pm 33$ & $212 \pm 35$ & $210 \pm 36$ & $208 \pm 32$ & 0.48 \\
\hline Triglyceride (mg dl-1) & $100(72-146)$ & $99(68-136)$ & $100(64-128)$ & $102(75-149)$ & 0.54 \\
\hline HDL-cholesterol (mg dl-1) & $56 \pm 15$ & $55 \pm 16$ & $56 \pm 16$ & $57 \pm 14$ & 0.39 \\
\hline Glucose (mg dl-1) & $95 \pm 17$ & $94 \pm 18$ & $92 \pm 20$ & $95 \pm 16$ & 0.31 \\
\hline hs-CRP (mg dl-1) & $0.029(0.015-0.064)$ & $0.031(0.018-0.072)$ & $0.030(0.015-0.066)$ & $0.028(0.013-0.052)$ & 0.66 \\
\hline
\end{tabular}

Abbreviations: HDL, high-density lipoprotein; hs-CRP, high-sensitivity C-reactive protein.

Values are mean \pm s.d., median (and interquartile range) and percentage.

$\mathrm{a}, \mathrm{b} P=0.03$ vs. no depression. 
Table 2 The changes of blood pressure values at baseline and after 3 years of follow-up

\begin{tabular}{lccc}
\hline & & Depression & No. $(\mathrm{n}=648)$ \\
\cline { 2 - 4 } & Persistent $(\mathrm{n}=104)$ & Transient $(\mathrm{n}=76)$ & $118 \pm 10$ \\
\hline Systolic blood pressure & & & $122 \pm 10$ \\
Baseline (mm Hg) & $120 \pm 11$ & $117 \pm 12$ & $3 \pm 1$ \\
After (mm Hg) & $123 \pm 12$ & $42 \pm 13$ & 0.05 \\
$\Delta$ Blood presssure & $3 \pm 1$ & & 0.67 \\
& & $76 \pm 10$ & $74 \pm 5$ \\
Diastolic blood pressure & $74 \pm 8$ & $77 \pm 10$ & $75 \pm 5$ \\
Baseline (mm Hg) & $76 \pm 9$ & $2 \pm 1$ & $2 \pm 1$ \\
After (mm Hg) & $3 \pm 1$ & 0.06 \\
$\Delta$ Blood presssure & & 0.46 \\
\hline
\end{tabular}

Blood pressure was measured in the sitting position after at least a 5-min rest by a trained nurse using a standard mercury sphygmomanometer.

a

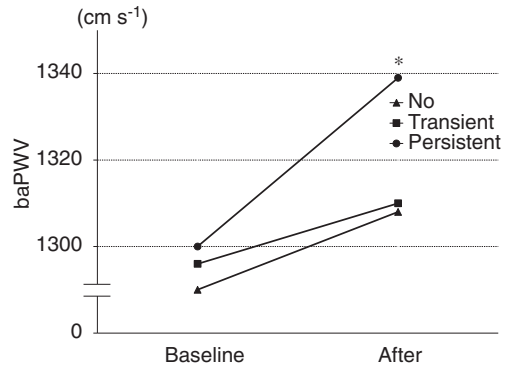

b

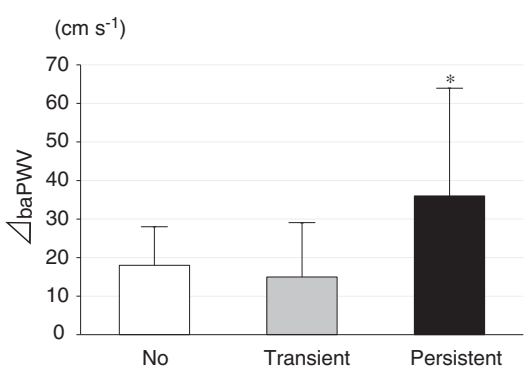

Figure 1 (a) Changes in brachial-ankle pulse wave velocity (baPWV) values at baseline and after 3 years of follow-up. Comparisons between baseline and subsequent baPWV values were performed by unadjusted analysis. ${ }^{*} P=0.02$ vs. no depression. (b) $\triangle \mathrm{baPWV}$ values according to the presence of depression. $\triangle$ baPWV values and depressive symptoms were compared by unadjusted analysis. ${ }^{*} P=0.02$ vs. no depression.

Figure $1 \mathrm{~b}$ shows the $\triangle \mathrm{baPWV}$ values according to the presence of depression. The $\triangle \mathrm{baPWV}$ was significantly higher in the subjects with persistent depression than in those with no depression $(36 \pm 28 v s$. $\left.18 \pm 10 \mathrm{~cm} \mathrm{~s}^{-1}, P=0.02\right)$.

Table 3 shows the correlation coefficients between $\triangle \mathrm{baPWV}$ and the other variables as determined via linear regression analysis. Depression, age, BMI, smoking, exercise, family history of hypertension, high-density lipoprotein-cholesterol, glucose, hs-CRP and baseline systolic blood pressure were significantly associated with $\triangle \mathrm{baPWV}$.

Table 4 shows the multivariate predictors of $\triangle \mathrm{baPWV}$ as determined via multiple regression analysis. Depression, age, BMI and baseline systolic blood pressure were significant and independent risk factors for $\triangle \mathrm{baPWV}$. The beta value of depression for $\triangle \mathrm{baPWV}$ values was $0.261(P<0.01)$.

\section{DISCUSSION}

The present study demonstrated that persistent depression was a significant risk factor for the development of arteriosclerosis in middle-aged Japanese male subjects.

Previous studies demonstrated that depression was closely associated with the morbidity and mortality of cardiovascular diseases. ${ }^{3,4,6,7}$ However, the relationship between depression and the development of arteriosclerosis has not been consistent.

Tiemeier et al. ${ }^{22}$ demonstrated that depression was significantly associated with arteriosclerosis, as evaluated by carotid-femoral pulse wave velocity, in a population-based study. Rajagopalan et al. ${ }^{23}$ also
Table 3 Correlation coefficients on linear regression analysis between $\triangle$ baPWV and variables

\begin{tabular}{lrr}
\hline & $r$ & P-value \\
\hline Depression & 0.32 & $<0.01$ \\
Age & 0.29 & $<0.01$ \\
Body mass index & 0.30 & $<0.01$ \\
Smoking & 0.19 & 0.04 \\
Alcohol & -0.15 & 0.14 \\
Exercise & -0.20 & 0.02 \\
Family history of hypertension & 0.26 & 0.02 \\
Total cholesterol & 0.03 & 0.56 \\
Triglyceride & 0.11 & 0.22 \\
HDL-cholesterol & 0.27 & 0.02 \\
Glucose & 0.20 & 0.04 \\
hs-CRP & 0.24 & 0.03 \\
Baseline systolic blood pressure & 0.36 & $<0.01$ \\
\hline
\end{tabular}

Abbreviations: $\triangle$ baPWV, changes in the brachial-ankle pulse wave velocity; $\mathrm{HDL}$, high-density lipoprotein; hs-CRP, high-sensitivity C-reactive protein.

Depression was defined as 'persistent depression' that had the Center for Epidemiological

Studies-Depression scores $\geqslant 16$ at all three times during the follow-up.

confirmed the relationship between arteriosclerosis and depression by brachial artery flow-mediated vasodilation.

In contrast, this association was not found in other studies in which arteriosclerosis was evaluated by coronary artery calcification. ${ }^{14,24}$ However, these studies evaluated depression only once during the study period. Depressive symptoms may be the expression of an acute 
Table 4 Multivariate predictors for $\triangle \mathrm{baPWV}$ by multiple regression analysis

\begin{tabular}{lrrrr}
\hline & $\mathrm{R}^{2}$ & \multicolumn{1}{c}{$\beta$} & \multicolumn{1}{c}{$95 \% \mathrm{Cl}$} & P-value \\
\hline Depression & 0.102 & 0.261 & $0.198-0.324$ & $<0.01$ \\
Age & 0.084 & 0.146 & $0.084-0.208$ & 0.01 \\
Body mass index & 0.090 & 0.152 & $0.086-0.218$ & $<0.01$ \\
Smoking & 0.036 & 0.058 & $0.009-0.107$ & 0.05 \\
Alcohol & 0.023 & -0.021 & $-0.064-0.022$ & 0.35 \\
Exercise & 0.040 & 0.013 & $-0.048-0.074$ & 0.48 \\
Family history of & 0.068 & 0.017 & $-0.069-0.103$ & 0.39 \\
hypertension & & & & \\
Total cholesterol & 0.001 & -0.019 & $-0.072-0.034$ & 0.37 \\
Triglyceride & 0.012 & 0.009 & $-0.041-0.059$ & 0.62 \\
HDL-cholesterol & 0.073 & -0.023 & $-0.065-0.019$ & 0.33 \\
Glucose & 0.040 & 0.018 & $-0.031-0.067$ & 0.41 \\
hs-CRP & 0.058 & 0.038 & $-0.011-0.087$ & 0.26 \\
Baseline systolic blood & 0.130 & 0.352 & $0.288-0.416$ & $<0.01$ \\
pressure & & & & \\
\hline
\end{tabular}

Abbreviations: $\triangle \mathrm{baPWV}$, changes in the brachial-ankle pulse wave velocity; $\beta$, standardized coefficients; $\mathrm{Cl}$, confidence interval; $\mathrm{HDL}$, high-density lipoprotein; hs-CRP, high-sensitivity C-reactive protein; $R^{2}$, partial determination coefficients.

C-reactive protein; $R^{2}$, partial determination coefficients.
Depression was defined as 'persistent depression' that had the Center for Epidemiological Studies-Depression scores $\geqslant 16$ at all three times during the follow-up.

Adjusted with age, body mass index, smoking, alcohol, exercise, family history of hypertension, total cholesterol, triglyceride, HDL-cholesterol, glucose, hs-CRP and baseline systolic blood pressure.

response to various stresses and may resolve over time. However, a subset of subjects remains persistently depressed, and this subset may be at higher risk for arteriosclerosis. Thus, the persistence of depression must be assessed. Moreover, persistent depression rather than transient depression may be more closely associated with the development of arteriosclerosis. However, few studies have examined the persistence of depression in healthy subjects, and, to our knowledge, no studies have assessed the relationship between the persistence of depression and the development of arteriosclerosis. In the present study, depression was evaluated at three time points over 3 years in parallel with the measurement of baPWV, which could allow the relationship between depression and arteriosclerosis to be clarified.

Hamer et al. ${ }^{16}$ demonstrated that long-term depressive symptoms assessed at different time points were associated with arteriosclerosis, as assessed by coronary artery calcification. Coronary artery calcification was a reliable predictor of coronary heart disease; ${ }^{25,26}$ however, this parameter could not be used to accurately evaluate systemic arteriosclerosis. ${ }^{16}$ The present study evaluated systemic arteriosclerosis using baPWV that could reflect the stiffness not only in the aorta but also in the total arterial tree. ${ }^{27}$ Therefore, the baPWV is considered to be a superior marker for the development of arteriosclerosis. In fact, Matsumoto et al..$^{28}$ demonstrated that the baPWV was a useful marker of subclinical atherosclerotic organ damage in middle-aged patients with hypertension. Recently, the 2007 European guidelines for the measurement of hypertension and the guidelines for coronary vascular disease prevention in clinical practice recommended aortic PWV for the assessment of atherosclerotic organ damage. ${ }^{29}$ There are several potential reasons why persistent depression was associated with the development of arteriosclerosis. Depression has been shown to increase systemic inflammatory biomarkers such as hs-CRP. ${ }^{30-32}$ In fact, hs-CRP values in subjects with persistent depression subjects tended to be higher than those in subjects with no depression in the present study. Low-grade inflammation may induce endothelial dysfunction by decreasing the bioavailability of nitric oxide through the inhibition of nitric oxide synthase. ${ }^{33}$ Moreover, endothelial dysfunction promotes the development of arteriosclerosis through the reduced availability of nitric oxide and increased vascular tone. ${ }^{34-36}$

The present study had several limitations that should be acknowledged. First, we examined the baPWV as an indirect marker of increased arterial stiffness, and we did not assess structural changes in the arterial wall. Second, we could not determine the pathophysiological mechanisms linking persistent depression and increased arterial stiffness in the present study. Third, the subjects included in our study were male workers aged 42-57 years because employees aged 40-60 years undergo annual health examinations that are performed by the company, and $\sim 92 \%$ of these employees were male. We were not able to include women or elderly subjects. Thus, the present findings should be applied cautiously to the general population. Fourth, a decrease in physical activity, an increase in alcohol intake and adoption of a smoking habit due to depression were important risk factors for the development of arteriosclerosis. However, unfortunately, we could not obtain information about the relationship between changes in habits, such as physical activity and alcohol intake, and depression because the subjects were only surveyed once a year.

In conclusion, persistent depression was significantly associated with the development of arteriosclerosis in middle-aged Japanese male subjects. Amelioration of mental stress may help to prevent atherosclerotic diseases.

\section{CONFLICT OF INTEREST}

The authors declare no conflict of interest.

1 Kessler RC, Berglund P, Demler O, Jin R, Koretz D, Merikangas KR, Rush AJ, Walters EE, Wang PS. The epidemiology of major depressive disorder: results from the National Comorbidity Survey Replication (NCS-R). JAMA 2003; 289: 3095-3105.

2 World Health organization. The World Health Report 2001-Mental Health: New Understanding. New Hope: Geneva, Switzerland, 2001.

3 Iso H, Date C, Yamamoto A, Toyoshima H, Tanabe N, Kikuchi S, Kondo T, Watanabe Y, Wada Y, Ishibashi T, Suzuki H, Koizumi A, Inaba Y, Tamakoshi A, Ohno Y. Perceived mental stress and mortality from cardiovascular disease among Japanese men and women: the Japan Collaborative Cohort Study for Evaluation of Cancer Risk Sponsored by Monbusho (JACC Study). Circulation 2002; 106: 1229-1236.

4 Musselman DL, Evans DL, Nemeroff CB. The relationship of depression to cardiovascular disease: epidemiology, biology, and treatment. Arch Gen Psychiatry 1998; 55: 580-592.

5 Pan A, Lucas M, Sun Q, van Dam RM, Franco OH, Manson JE, Willett WC, Ascherio A, $\mathrm{Hu}$ FB. Bidirectional association between depression and type 2 diabetes mellitus in women. Arch Intern Med 2010; 170: 1884-1891.

6 Pan A, Sun Q, Okereke OI, Rexrode KM, Hu FB. Depression and risk of stroke morbidity and mortality: a meta-analysis and systematic review. JAMA 2011; 306: 1241-1249.

7 Patten SB, Williams JV, Lavorato DH, Campbell NR, Eliasziw M, Campbell TS. Major depression as a risk factor for high blood pressure: epidemiologic evidence from a national longitudinal study. Psychosom Med 2009; 71: 273-279.

8 Patten SB, Williams JV, Lavorato DH, Modgill G, Jette N, Eliasziw M. Major depression as a risk factor for chronic disease incidence: longitudinal analyses in a general population cohort. Gen Hosp Psychiatry 2008; 30: 407-413.

9 Van der Kooy K, van Hout H, Marwijk H, Marten H, Stehouwer C, Beekman A. Depression and the risk for cardiovascular diseases: systematic review and meta analysis. Int J Geriatr Psychiatry 2007; 22: 613-626.

10 Satoh H, Saijo Y, Kishi R, Tsutsui H. Brachial-ankle pulse wave velocity is an independent predictor of incident hypertension in Japanese normotensive male subjects. Environ Health Prev Med 2011; 16: 217-223.

11 Shively CA, Register TC, Adams MR, Golden DL, Willard SL, Clarkson TB. Depressive behavior and coronary artery atherogenesis in adult female cynomolgus monkeys. Psychosom Med 2008; 70: 637-645.

12 Agatisa PK, Matthews KA, Bromberger JT, Edmundowicz D, Chang YF, Sutton-Tyrrell K. Coronary and aortic calcification in women with a history of major depression. Arch Intern Med 2005; 165: 1229-1236.

13 Faramawi MF, Gustat J, Wildman RP, Rice J, Johnson E, Sherwin R. Relation between depressive symptoms and common carotid artery atherosclerosis in American person$\mathrm{s}>$ or $=65$ years of age. Am J Cardiol 2007; 99: 1610-1613.

14 Diez Roux AV, Ranjit N, Powell L, Jackson S, Lewis TT, Shea S, Wu C. Psychosocial factors and coronary calcium in adults without clinical cardiovascular disease. Ann Intern Med 2006; 144: 822-831. 
15 Lewis TT, Sutton-Tyrrell K, Penninx BW, Vogelzangs N, Harris TB, Vaidean GD, Ayonayon HN, Kim L, Lakatta EG, Newman AB. Race, psychosocial factors, and aortic pulse wave velocity: the Health, Aging, and Body Composition Study. J Gerontol A Biol Sci Med Sci 2010; 65: 1079-1085.

16 Hamer M, Kivimaki M, Lahiri A, Marmot MG, Steptoe A. Persistent cognitive depressive symptoms are associated with coronary artery calcification. Atherosclerosis 2010; 210: 209-213.

17 Haringsma R, Engels GI, Beekman AT, Spinhoven P. The criterion validity of the Center for Epidemiological Studies Depression Scale (CES-D) in a sample of self-referred elders with depressive symptomatology. Int J Geriatr Psychiatry 2004; 19: 558-563.

18 Radloff LS. The CES-D scale: a self-reporot depression scale for research in the general population. Appl Psychol Meas. 1977; 1: 385-401.

19 Roberts RE, Vernon SW. The Center for Epidemiologic Studies Depression Scale: its use in a community sample. Am J Psychiatry 1983; 140: 41-46.

20 Weissman MM, Sholomskas D, Pottenger M, Prusoff BA, Locke BZ. Assessing depressive symptoms in five psychiatric populations: a validation study. Am J Epidemiol 1977; 106: 203-214.

21 Yamashina A, Tomiyama H, Takeda K, Tsuda H, Arai T, Hirose K, Koji Y, Hori S, Yamamoto Y. Validity, reproducibility, and clinical significance of noninvasive brachial-ankle pulse wave velocity measurement. Hypertens Res 2002; 25: 359-364.

22 Tiemeier H, Breteler MM, van Popele NM, Hofman A, Witteman JC. Late-life depression is associated with arterial stiffness: a population-based study. J Am Geriatr Soc 2003; 51: 1105-1110.

23 Rajagopalan S, Brook R, Rubenfire M, Pitt E, Young E, Pitt B. Abnormal brachial artery flow-mediated vasodilation in young adults with major depression. Am J Cardiol 2001; 88: 196-198.

24 O'Malley PG, Jones DL, Feuerstein IM, Taylor AJ. Lack of correlation between psychological factors and subclinical coronary artery disease. N Engl J Med 2000; 343: 1298-1304.

25 Folsom AR, Kronmal RA, Detrano RC, O'Leary DH, Bild DE, Bluemke DA, Budoff MJ, Liu K, Shea S, Szklo M, Tracy RP, Watson KE, Burke GL. Coronary artery calcification compared with carotid intima-media thickness in the prediction of cardiovascular disease incidence: the Multi-Ethnic Study of Atherosclerosis (MESA). Arch Intern Med 2008; 168: 1333-1339.

26 Greenland P, Bonow RO, Brundage BH, Budoff MJ, Eisenberg MJ, Grundy SM, Lauer MS, Post WS, Raggi P, Redberg RF, Rodgers GP, Shaw LJ, Taylor AJ, Weintraub WS, Harrington RA, Abrams J, Anderson JL, Bates ER, Grines CL,
Hlatky MA, Lichtenberg RC, Lindner JR, Pohost GM, Schofield RS, Shubrooks SJ Jr., Stein JH, Tracy CM, Vogel RA, Wesley DJ. ACCF/AHA 2007 clinical expert consensus document on coronary artery calcium scoring by computed tomography in global cardiovascular risk assessment and in evaluation of patients with chest pain: a report of the American College of Cardiology Foundation Clinical Expert Consensus Task Force (ACCF/AHA Writing Committee to Update the 2000 Expert Consensus Document on Electron Beam Computed Tomography). Circulation 2007; 115: 402-426.

27 Yu WC, Chuang SY, Lin YP, Chen CH. Brachial-ankle vs carotid-femoral pulse wave velocity as a determinant of cardiovascular structure and function. J Hum Hypertens 2008; 22: 24-31.

28 Matsumoto C, Tomiyama H, Yamada J, Yoshida M, Shiina K, Yamashina A. Brachialankle pulse wave velocity as a marker of subclinical organ damage in middle-aged patients with hypertension. J Cardiol 2008; 51: 163-170.

29 Mancia G, De Backer G, Dominiczak A, Cifkova R, Fagard R, Germano G, Grassi G, Heagerty AM, Kjeldsen SE, Laurent S, Narkiewicz K, Ruilope L, Rynkiewicz A, Schmieder RE, Boudier HA, Zanchetti A. ESH-ESC Practice Guidelines for the Management of Arterial Hypertension: ESH-ESC Task Force on the Management of Arterial Hypertension. J Hypertens 2007; 25: 1751-1762.

30 Brydon L, Walker C, Wawrzyniak A, Whitehead D, Okamura H, Yajima J, Tsuda A, Steptoe A. Synergistic effects of psychological and immune stressors on inflammatory cytokine and sickness responses in humans. Brain Behav Immun 2009; 23: 217-224.

31 Hansel A, Hong S, Camara RJ, von Kanel R. Inflammation as a psychophysiological biomarker in chronic psychosocial stress. Neurosci Biobehav Rev 2009; 35: 115-121.

32 Koo JW, Russo SJ, Ferguson D, Nestler EJ, Duman RS. Nuclear factor-kappaB is a critical mediator of stress-impaired neurogenesis and depressive behavior. Proc Natl Acad Sci USA 2010; 107: 2669-2674.

33 Venugopal SK, Devaraj S, Yuhanna I, Shaul P, Jialal I. Demonstration that C-reactive protein decreases eNOS expression and bioactivity in human aortic endothelial cells. Circulation 2002; 106: 1439-1441.

34 Anderson TJ, Uehata A, Gerhard MD, Meredith IT, Knab S, Delagrange D, Lieberman EH, Ganz P, Creager MA, Yeung AC et al. Close relation of endothelial function in the human coronary and peripheral circulations. J Am Coll Cardiol 1995; 26: 1235-1241.

35 Williams JK, Kaplan JR, Manuck SB. Effects of psychosocial stress on endothelium mediated dilation of atherosclerotic arteries in cynomolgus monkeys. J Clin Invest 1993; 92: 1819-1823.

36 Strawn WB, Bondjers G, Kaplan JR, Manuck SB, Schwenke DC, Hansson GK, Shively CA, Clarkson TB. Endothelial dysfunction in response to psychosocial stress in monkeys. Circ Res 1991; 68: 1270-1279. 